\title{
Determination of Temperature Sensitive Plasmid Copy Number in Escherichia coli by Absolute and Relative Real Time Quantitation PCR
}

\author{
Xianzhang Jiang, ${ }^{1}$ Hongjiao Liu, ${ }^{1}$ Yongchao Niu, ${ }^{1}$ Meirong Hu, ${ }^{2}$ Feng Qi, ${ }^{1}$ Mingliang Zhang, ${ }^{1}$ Jianzhong \\ Huang, ${ }^{1,}{ }^{*}$ and Yong $\mathrm{TaO}^{2,{ }^{*}}$ \\ ${ }^{1}$ Engineering Research Center of Industrial Microbiology, College of Life Sciences, Fujian Normal University, Fuzhou, Fujian 350117, People's Republic of China \\ ${ }^{2}$ Institute of Microbiology, Chinese Academy of Sciences, Beijing, 100101, People's Republic of China \\ "Corresponding authors: Jianzhong Huang, Engineering Research Center of Industrial Microbiology, College of Life Sciences, Fujian Normal University, Fuzhou, Fujian 350117 \\ People's Republic of China. Tel/Fax: +86-5912286-8212, E-mail: hjz@fjnu.edu.cn; Yong Tao, Institute of Microbiology, Chinese Academy of Sciences, Beijing, 100101, People's \\ Republic of China. Tel/Fax: +86-1064807419, E-mail: taoyong@im.ac.cn
}

Received 2016 September 08; Revised 2017 February 17; Accepted 2017 March 09.

\begin{abstract}
Background: Temperature sensitive plasmid pBBR1MCS2-Ts, mutated from pBBR1MCS and derived from pBBR1, is a broad host range plasmid and it is especially useful for gene targeting and integration in various hosts. The plasmid copy number (PCN) of temperature sensitive plasmid in host mainly depends on the stability of plasmid.

Objectives: The present study aimed at investigating the PCN of pBBR1MCS2-Ts and pBBR1MCS2 at permissive $\left(30^{\circ} \mathrm{C}\right)$ or nonpermissive $\left(42^{\circ} \mathrm{C}\right)$ temperatures.

Methods: The rep gene in the plasmid and the $d x s$ gene in the Escherichia coli genome were used as target and reference gene. A standard plasmid pLB1k-dxs-rep was constructed for real time PCR calibration. The PCNs were calculated by absolute and relative quantitation. Total DNA of E. coli T1 harboring plasmid pBBR1MCS2 or pBBR1MCS2-Ts were extracted and real time qPCR were performed in triplicate, with 2 independent biological replicates.

Results: The primer sets Qrep and Q $d x s$ produced specific products and could be used to detect the target plasmid and chromosomal DNA, respectively. The PCN determined by the absolute and relative quantitation PCR were similar and reproducible. The PCN of pBBR1MCS2 in E. coli was about 19 when cultured at $30^{\circ} \mathrm{C}$ and about 10 when cultured at $42^{\circ} \mathrm{C}$, and the PCN of pBBR1MCS2-Ts was about 6 when cultured at $30^{\circ} \mathrm{C}$ and nearly zero when cultured at $42^{\circ} \mathrm{C}$. Compared with pBBR1MCS2, the temperature shift from $30^{\circ} \mathrm{C}$ to $42^{\circ} \mathrm{C}$ caused a significant decrease in the PCN of temperature sensitive plasmid pBBR1MCS2-Ts.

Conclusions: The PCN of temperature sensitive plasmid was very low at $42^{\circ} \mathrm{C}$ and temperature sensitivity of the plasmid was mainly caused by the mutation of rep ORF, which subsequently affected the plasmid replication and stability.
\end{abstract}

Keywords: Real Time Polymerase Chain Reaction, Plasmid, Copy Number, Method, Escherichia coli

\section{Background}

Bacterial plasmids are widely used as cloning vehicles in molecular cloning and expression. Modification of plasmids to facilitate gene manipulation is an active research topic in biotechnology, because plasmid is the basic tool for carrying foreign genes into host cell. Temperature sensitive modifications of plasmids are especially useful for plasmid curing (1), homologous recombination (2), protein expression (3), and transposon mutagenesis (4). They are able to replicate at a permissive temperature in hosts but could be easily eliminated by elevating the temperature to nonpermissive conditions. A series of temperature sensitive plasmids have been developed (5) and applied for patents (6-8). However, few of them focus on the plasmid copy number of temperature sensitive plasmid.

The plasmid copy number (PCN) is defined as the number of copies of a plasmid present per chromosome in a cell (9). The PCN is a key feature of a plasmid and is largely controlled by the origin of replication (10). Traditionally, PCN was analyzed by $\mathrm{CsCl}$ gradient centrifugation (11), fluorescence densitometry (12), high-pressure liquid chromatography (13), DNA hybridization (14), or capillary electrophoresis (15). However, these methods are laborious, time consuming, and costly. Recently, a novel approach to determine PCN using real time quantitative PCR (qPCR) technology has been developed $(9,16)$. Real time qPCR offers numerous advantages over traditional methods including saving time, rapid procedure, high sensitivity and precision, wide range of quantification, and use of small amounts of sample (17).

Broad host range plasmids are of considerable interest due to their ability to maintain stability in various hosts and their application in recombinant DNA technology. The commercially available plasmid pBBR1MCS2 (18), derived from pBBR1 and isolated from Bordetella bronchiseptica (19), 
is a mobilizable broad host range plasmid. It contains $3 \mathrm{im}$ portant open reading frames (ORFs). The first ORF is rep, involved in plasmid replication; the second is mob, involved in mobilization; and the third encodes aminoglycoside 3'-phosphotransferase, involved in kanamycin resistance (Figure 1). To extend the utility of plasmid pBBR1MCS2, we mutated the rep gene and its promoter and terminator by error prone PCR and screened for temperature sensitivity in our pervious study (20).

One mutant plasmid (pBBR1MCS2-Ts) was identified that could be maintained in Escherichia coli 11 when grown at $30^{\circ} \mathrm{C}$ but was lost from host cells when grown at $42^{\circ} \mathrm{C}$ in the absence of antibiotic selection. Plasmid pBBR1MCS2 is a widely used commercial plasmid and does not belong to the known broad host range IncP, IncQ, or IncW groups; however, its replication mechanism remains elusive (19). Due to lack of knowledge about pBBR1MCS2 replication, the temperature sensitive mechanism of pBBR1MCS2-Ts is yet to be characterized. In our previous work (20), pBBR1MCS2-Ts was lost from $99.99 \%$ of host E. coli after being incubated for 18 hours at $42^{\circ} \mathrm{C}$, therefore, it is necessary to quantify the copy number of pBBR1MCS2 and pBBR1MCS2-Ts in the host cell at permissive and nonpermissive temperature.

Figure 1. The Sketch of Broad Host Range Plasmid pBBR1MCS2

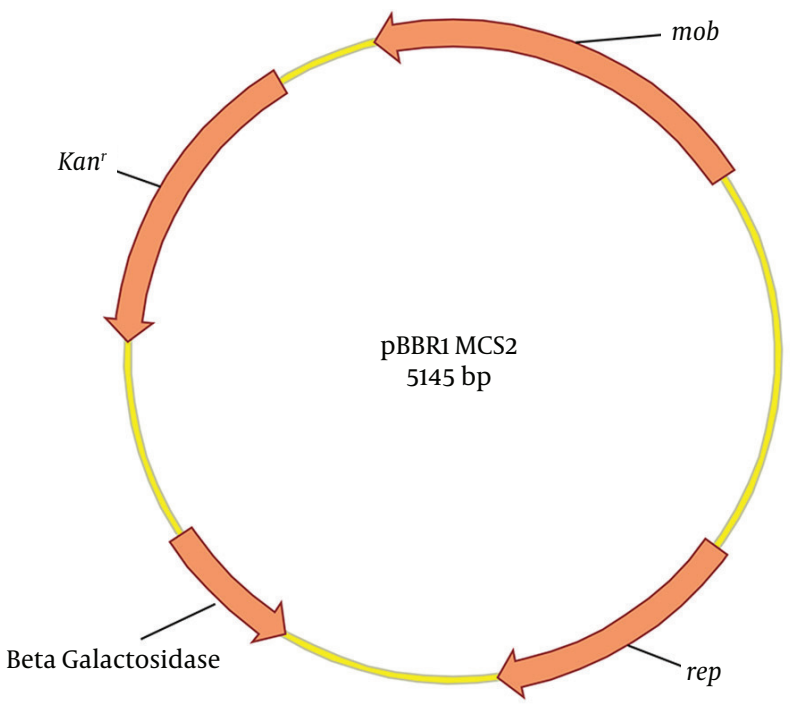

The plasmid contains 3 important open reading frames (ORFs). The first ORF is rep, involved in plasmid replication; and the second is mob, involved in mobilization; and the third encodes aminoglycoside 3'-phosphotransferase, involved in kanamycin resistance.

\section{Objectives}

The current study aimed at investigating the PCN of temperature sensitive and broad host range plasmid in $E$. coli by absolute and relative real time qPCR. Determining the plasmid copy number of temperature sensitive mutant pBBR1MCS2-Ts will help reveal replication mechanism of pBBR1MCS2.

\section{Methods}

\subsection{Cultivation of Escherichia coli}

Escherichia coli $\mathrm{T} 1$ was used as host for the plasmids pBBR1MCS2 and pBBR1MCS2-Ts. Escherichia coli DH5 $\alpha$ was used for standard plasmid construction. Escherichia coli T1 harboring plasmid pBBR1MCS2 or pBBR1MCS2-Ts were inoculated into $3 \mathrm{~mL}$ of Luria-Bertani (LB) medium with 50 $\mu \mathrm{g} / \mathrm{mL}$ of kanamycin in $15 \times 150 \mathrm{~mm}$ test tubes and grown at $30^{\circ} \mathrm{C}$ for 18 hours. Two $3 \mu \mathrm{L}$ portions of the overnight culture were inoculated into fresh $3 \mathrm{~mL} \mathrm{LB}$ media without kanamycin. One portion of E. coli 11 containing pBBR1MCS2 or pBBR1MCS2-Ts was grown at $30^{\circ} \mathrm{C}$ for 18 hours and the other portion was grown at $42^{\circ} \mathrm{C}$ for 18 hours.

\subsection{Construction of Standard Plasmid for Real-Time PCR Cali- bration}

To quantify the plasmid copy number (PCN) of pBBR1MCS2 or pBBR1MCS2-Ts, a standard plasmid pLB1k$d x s$-rep was constructed (Figure 2). The rep is a singlecopy gene of pBBR1MCS2 and the 1-deoxy-D-xylulose-5phosphate synthase gene $(d x s)$ is a single-copy gene of $E$. coli genome (21). The fragments of PLB1K, rep and $d x$ s were amplified by PCR in a $100 \mu$ L reaction mixture composed of $5 \times$ Q5 Reaction buffer (New England Biolabs) $20.0 \mu \mathrm{L}$, template $2.0 \mu \mathrm{L}$, forward and reverse primers (Table 1) $4 \mu \mathrm{L}$ each, $10 \mathrm{mM}$ dNTP $2 \mu \mathrm{L}$, Q5 High-Fidelity DNA Polymerase (New England Biolabs) $1.0 \mu \mathrm{L}$, and $67.0 \mu \mathrm{L}$ of $\mathrm{ddH}_{2} \mathrm{O}$ to bring the total reaction volume to $100 \mu \mathrm{L}$. After initial denaturation at $95^{\circ} \mathrm{C}$ for 5 minutes, amplification was performed in 30 cycles of 20 seconds at $95^{\circ} \mathrm{C}, 20$ seconds at $58^{\circ} \mathrm{C}$, and $2,0.5$, or 1 minutes at $72^{\circ} \mathrm{C}$ (for the pLB1k, rep or $d x s$ fragment, respectively), followed by a final extension at $72^{\circ} \mathrm{C}$ for 7 minutes. The 3 fragments were gel-purified and mixed equimolar amounts totaling $5 \mu \mathrm{L}$ with $15 \mu \mathrm{L}$ Gibson Assembly Master Mix (New England Biolabs) (22). After incubation at $50^{\circ} \mathrm{C}$ for 1 hour, $10 \mu \mathrm{L}$ reaction mixture was transformed into E. coli $\mathrm{DH} 5 \alpha$. The positive colony harboring pLB1K-dxs-rep was selected by PCR verification and sequencing. 
Table 1. Primers Used in This Study

\begin{tabular}{|c|c|c|c|}
\hline Primer & Sequence (5'-3') & Length (nt) & Ref. \\
\hline GpLB1kR & GGTTAATTCCTCCTGTTAGCC & 21 & This work \\
\hline GpLB1kF & CTGCAGCTGGTGCCGCGCGGC & 21 & This work \\
\hline GrepF & CTGGCTGGCATAAATGGCCACGCAGTCCAGAGAAATCGG & 51 & This work \\
\hline GrepR & GGCTGCCGCGCGGCACCAGCTGCAGCTACCGGCGCGGCAGCGTGAC & 34 & This work \\
\hline GdxsF & TTTGGGCTAACAGGAGGAATTAACCATGGGTTTTGATATTGCCAAATACCC & 39 & This work \\
\hline GdxsR & ACTGCGTGGCCATTTATGCCAGCCAGGCCTTGAT & 46 & This work \\
\hline QrepF & GCATTCAAGCCAAGAACAAG & 20 & This work \\
\hline QrepR & GTGGGTTTCCTCGCAATAAG & 20 & This work \\
\hline QdxsF & CGAGAAACTGGCGATCCTTA & 20 & $(16)$ \\
\hline QdxsR & CTTCATCAAGCGGTTTCACA & 20 & $(16)$ \\
\hline M13F & CGCCAGGGTTTTCCCAGTCACGAC & 24 & $(23)$ \\
\hline M13R & AGCGGATAACAATTTCACACAGGA & 24 & (23) \\
\hline
\end{tabular}

Figure 2. The Sketch of Standard Plasmid pLB1K-dxs-rep for Real Time PCR Calibration

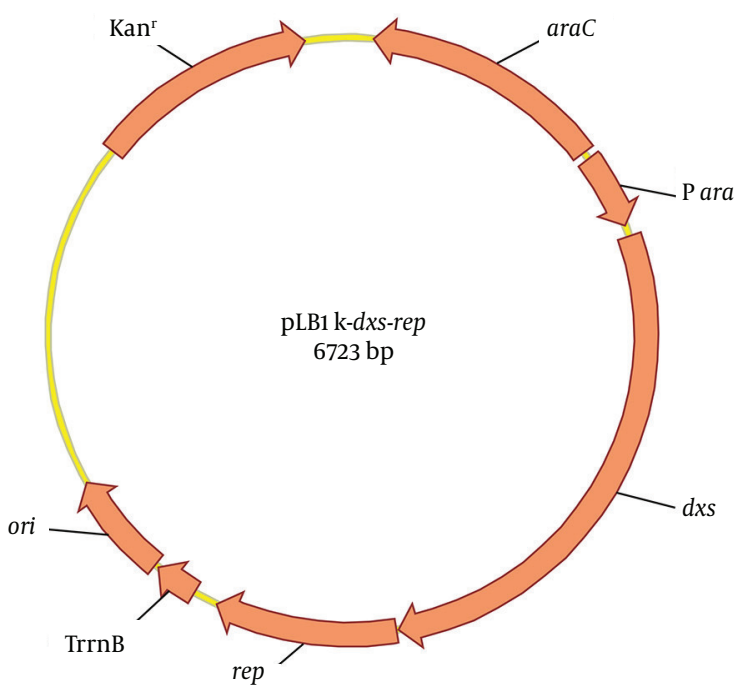

The rep is a single-copy gene of pBBR1MCS2 and the 1-deoxy-D-xylulose-5-phosphate synthase gene $(d x s)$ is a single-copy gene of $E$. coli genome. The fragments of pLB1k, $d x$ and rep were assembled by Gibson assembly.

\subsection{Total DNA and Plasmid Extraction for Real Time PCR}

The total DNA of E. coli T1 harboring plasmid pBBR1MCS2 or pBBR1MCS2-Ts cultured at $30^{\circ} \mathrm{C}$ or $42^{\circ} \mathrm{C}$ were extracted by TIANamp Bacteria DNA Kit (Tiangen Corporation) according to the manufacturer's instructions. The standard plasmid DNA was isolated by Plasmid
Mini Kit I (Omega BIO-TEK). The concentration of the standard plasmid was determined using a BioSpec-nano spectrophotometer (Shimadzu). The copy number was calculated according to the equation (24):

\subsection{Real Time PCR}

Two sets of gene specific primers, QrepF, QrepR and $\mathrm{Q} d x s \mathrm{~F}, \mathrm{Q} d x \mathrm{~s} \mathrm{R}$ (Table 1) were designed using Beacon Designer (Version 8.14) for real time qPCR according to the sequence of rep and $d x$ gene. The PCR fragments of rep and $d x s$ were amplified by conventional PCR, gel-purified and inserted into pGEM-T vector (Promega Corporation) by T4 ligase. Five microliter of the ligation mixture was used to transform E. coli DH5 $\alpha$ for ampicillin resistance. The positive transformants were confirmed by PCR using M13 forward and reverse primers (Table 1 ) and sequenced by ABI sequencer (Applied Biosystems). Serial 10-fold dilutions of purified and quantified standard plasmid pLB1k- $d x s-r e p$ were used as standard templates.

Real time PCR was conducted in a LightCycler®96 instrument (Roche Life Science).The PCR was performed in a $10 \mu$ L reaction mixture composed of $2 \times$ SYBR Green I PCR Master Mix (Roche Life Science) $5.0 \mu \mathrm{L}$, template $0.5 \mu \mathrm{L}$, forward and reverse real time PCR primers (Table 1) $0.2 \mu \mathrm{L}$ each, and $4.1 \mu \mathrm{L}$ of $\mathrm{ddH}_{2} \mathrm{O}$ to bring the total reaction volume to $10 \mu \mathrm{L}$. The real time PCR conditions were as follow: a 10- minute initial denaturation at $95^{\circ} \mathrm{C} ; 45$ cycles of 10 seconds at $95^{\circ} \mathrm{C} ; 10$ seconds at $60^{\circ} \mathrm{C} ; 10$ seconds at $72^{\circ} \mathrm{C}$; and a melting curve step (from $65^{\circ} \mathrm{C}$, gradually increasing $0.2^{\circ} \mathrm{C} / \mathrm{s}$ to $97^{\circ} \mathrm{C}$, with continuous fluorescence measurement). The results were analyzed using the LightCycler® data analysis software Version 1.1 (Roche Life Science). 
Numberofcopies $/ \mu L=\frac{6.022 \times 10^{23}\left(\frac{\text { Molecules }}{\text { mol }}\right) \times \text { DNAconcentration }(g / L)}{\text { Numberofbasespairs } \times 660 \text { daltons }}$

\subsection{Absolute and Relative Quantitation}

Absolute quantification determines the copy numbers by relating the measured cycle threshold (CT) value to the standard curve that can be obtained by serially diluting the standard plasmid of which the DNA concentration and molecular weight is known(25). Cycle threshold values can thereby be related to the gene copy number. Cycle threshold values in each dilution were determined in duplicate and plotted against the logarithm concentrations of the plasmid copies. Each standard curve was generated by a correlation coefficient $\left(\mathrm{R}^{2}\right)$ of the plotted points. The PCR amplification efficiency (E) has a major impact on the accuracy of the absolute quantification and is calculated from the slope of each standard curve using the following equation (26):

$E=10^{-1 / \text { Slope }}-1$

Relative quantification determines the gene copy numbers by comparative $C_{T}\left(2^{-\Delta \Delta C_{T}}\right)$ method which compares the CT value of interest gene in plasmid to the control gene in genome (27). The relative PCN was calculated according to the following equation (16):

Relative $P C N=(1+E)^{\Delta \Delta C_{T}}$

Whereby $\Delta \Delta \mathrm{C}_{\mathrm{T}}: \Delta \mathrm{C}_{\mathrm{TSample}}-\Delta \mathrm{C}_{\mathrm{T}}$ Calibrator. $\Delta \mathrm{C}_{\mathrm{T}}$ : $\mathrm{C}_{\mathrm{TTarget}}-\mathrm{C}_{\mathrm{TReference}}$. Target: rep gene in pBBR1MCS -2 or pBBR1MCS2-Ts. Reference: $d x$ s gene in E. coli genome. Sample: total DNA extracted from the E. coli T1. Calibrator: standard plasmid pLB1k-dxs-rep.

Statistical analysis was done by t-test analysis using false discovery rate (FDR) approach. Coefficient of variation was used to assess the variability of quantitative assays, which was calculated according to the following equation (28):

$C V \%=S D /$ mean $\times 100 \%$

Where SD: Standard deviation.

\section{Results}

\subsection{Confirmation of Primer Specificity}

SYBR Green I is a nonspecific intercalating dye and binds to the minor groove of the double-stranded DNA in a sequence-independent way. Both specific and nonspecific PCR fragments formed will be detected. To verify the specific of real time PCR, both melting curve and gel analysis were performed (Figure 3). The Qrep primer set (Figure 3A) produced a single, sharp melting peak at $86.0^{\circ} \mathrm{C}$ when using pLB1k-dxs-rep standard plasmid and E. coli total DNA as template. The Qdxs primer set (Figure $3 \mathrm{~B}$ ) also produced a single, sharp melting peak at $84.5^{\circ} \mathrm{C}$ when using pLB1k$d x s$-rep standard plasmid and $E$. coli total DNA as qPCR template. Gel electrophoresis analysis of the PCR products also showed a single band of expected size. The amplified products also confirmed by DNA sequencing. These results indicated that nonspecific products were not generated during the 45 real time PCR amplification cycles.

\subsection{Standard Curves and $\Delta \Delta C T$ Validation}

The standard curves were made by 10 -fold serial dilutions of known amounts of standard plasmid pLB1k-dxs-rep (Figure 4A). Both of the standard curves for rep and $d x$ shad a linear range between $3 \times 10^{6}$ and $3 \times 10^{9}$ copies $/ \mu \mathrm{L}$ with slopes of -3.443 and -3.438 , respectively, which were nearly equal. Both of the genes had a high amplification efficiency of 0.95 with $\mathrm{R}^{2}$ value (square regression coefficient) $>0.99$.

For the $\Delta \Delta \mathrm{CT}$ calculation to be valid, the amplification efficiencies of the target and reference gene must be approximately equal (26). The CT deviation between rep and $d x s$ ( $\Delta$ CT Calibrator) with plasmid dilution was calculated to assess the amplification efficiency (rage $\Delta$ CT Calibrator is 0.81 and the slope of linear regression line was close to zero (-0.008) which indicated that the E (rep) and $\mathrm{E}(d x s)$ are similar enough for the $\Delta \Delta \mathrm{CT}$ calculation (16). The relationship between CT and gene copy number was used for absolute quantification and the amplification efficiency and $\Delta \mathrm{CT}$ Calibrator were used for relative quantification.

\subsection{Determination of Plasmid Copy Number by Absolute Quan- tification}

Two separate cultures of E. coli $\mathrm{T} 1$ harboring plasmid pBBR1MCS2 or pBBR1MCS2-Ts were grown at permissive $\left(30^{\circ} \mathrm{C}\right)$ or nonpermissive $\left(42^{\circ} \mathrm{C}\right)$ temperatures. Total DNA was extracted and real time qPCR were performed in triplicate, with 2 independent biological replicates. The absolute copy numbers of rep and $d x$ s in the E. coli were calculated from the corresponding standard curve. Because the $d x$ s gene is a single-copy gene of E. coli genome, the PCN of the pBBR1MCS2 or pBBR1MCS2-Ts could be calculated as ratio of rep to $d x$ s. Table 2 displays the results of the absolute quantification and the PCN. The PCN of pBBR1MCS2 in E. coli 
A

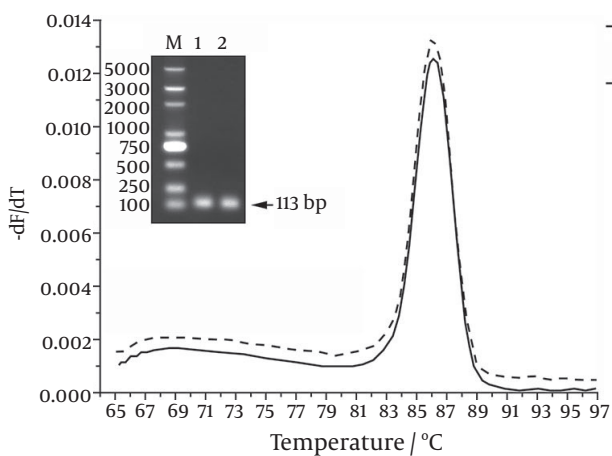

B

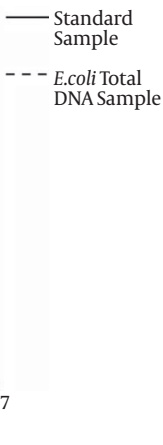

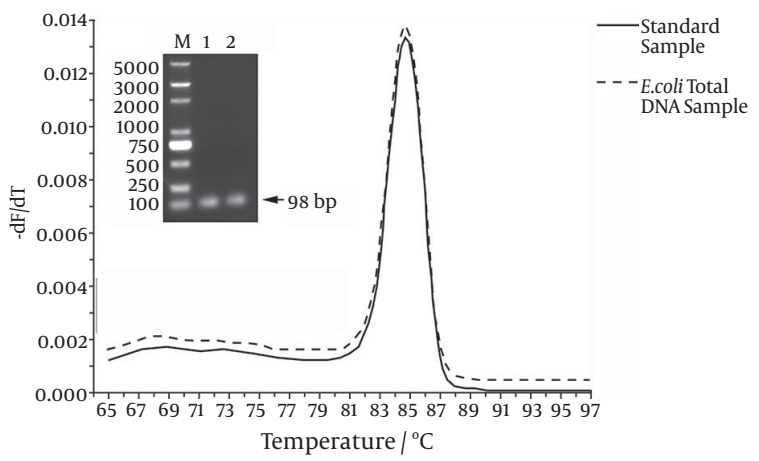

The Orep primer set (A) produced a single, sharp melting peak at $86.0^{\circ} \mathrm{C}$ when using pLB1k- $d x s-r e p$ standard plasmid and $E$. coli total DNA as template. The Odxs primer set (B) also produced a single, sharp melting peak at $84.5^{\circ} \mathrm{C}$ when using pLB1k-dxs-rep standard plasmid and $E$. coli total DNA as qPCR template. Gel electrophoresis analysis of the PCR products also showed a single band of expected size.

Figure 4. Determination of Real Time PCR Efficiencies of A, rep Gene and dxs Target Gene and B, Calculation of $\Delta \mathrm{CT}$

A

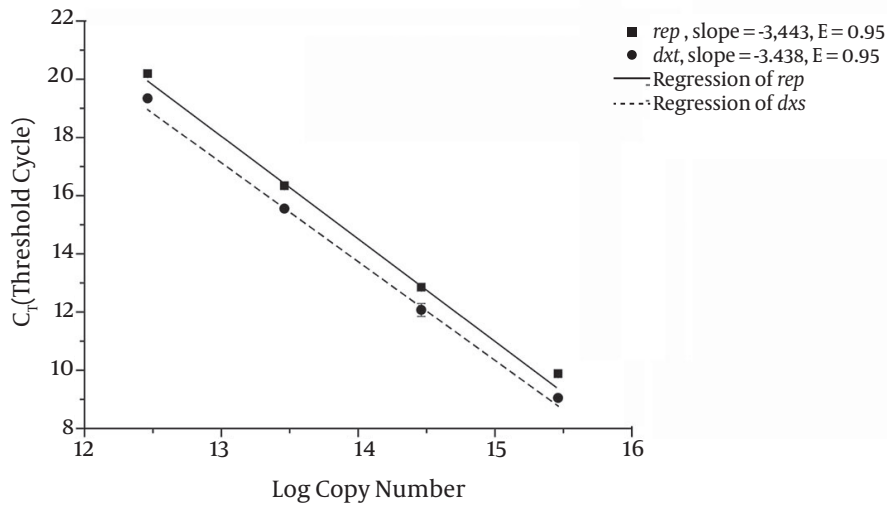

B

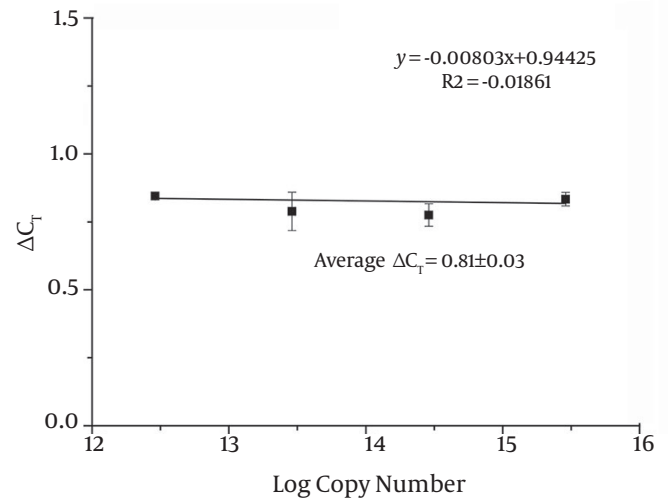

The standard curves were made by 10 -fold serial dilutions of pLB1k- $d x s$-rep $(\mathrm{n}=3)$. Both of the standard curves for rep and $d x$ shad a linear range between $3 \times 10^{6}$ and $3 \times 10^{9}$ copies $/ \mu$ L with slopes of -3.443 and -3.438 , respectively, which were nearly equal. Both of the genes had a high amplification efficiency of 0.95 with $\mathrm{R}^{2}$ value (square regression coefficient $)>0.99$. The $\mathrm{CT}$ deviation of rep versus $d x s(\Delta \mathrm{CT})$ was calculated for each dilution and plotted $(\mathrm{n}=8)$.

was 19.56 when cultured at $30^{\circ} \mathrm{C}$ and was 10.07 when cultured at $42^{\circ} \mathrm{C}$, however, the PCN of temperature sensitive plasmid pBBR1MCS2-Ts derived from pBBR1MCS2 in E. coli was 6.16 when cultured at $30^{\circ} \mathrm{C}$ and almost zero when cultured at $42^{\circ} \mathrm{C}$. The PCNs of pBBR1MCS2 and pBBR1MCS2-Ts decreased as the culture temperature increased from $30^{\circ} \mathrm{C}$ to $42^{\circ} \mathrm{C}$ and the PCNs of pBBR1MCS2 were apparently higher than those of pBBR1MCS2-Ts either cultured at $30^{\circ} \mathrm{C}$ or $42^{\circ} \mathrm{C}$.

\subsection{Determination of PCN by Relative Quantification}

For relative quantification, the ratio of target gene to reference gene in the total DNA of E. coli was normalized by the target gene to reference gene ratio in the calibrator. The rep gene and $d x$ sene were used as the target and the reference gene, respectively, and the standard plasmid pLB1K- $d x$ s-rep, which contained single copy of rep and $d x$ s gene, was used as calibrator. The $\Delta$ CT Calibrator was calculated by averaging the $\Delta \mathrm{CT}$ values calculated from the 10 -fold serial dilutions of the pLB1K-dxs-rep (Figure 4B). Using the estimated $\mathrm{E}$ values from the slopes of the standard curve, the PCN of pBBR1MCS2 and pBBR1MCS2-Ts in E. coli at different temperatures were calculated by relative quantification (Table 3). The PCN of pBBR1MCS2 in E. coli was 
Table 2. Determining the Plasmid Copy Number of pBBR1MCS-2 and pBBR1MCS-2-Ts in E. coli by Absolute Quantification

\begin{tabular}{|c|c|c|c|c|c|c|}
\hline \multirow[t]{2}{*}{ E. coli Harboring Plasmid } & \multirow[t]{2}{*}{ Culture Temperature, ${ }^{\circ} \mathrm{C}$} & \multicolumn{2}{|c|}{$\mathbf{C T}^{\mathbf{a}}$} & \multicolumn{2}{|c|}{ Copies $^{\mathbf{b}}$, Copies $/ \mu \mathbf{L}$} & \multirow[t]{2}{*}{$\mathbf{P C N}^{\mathrm{c}}$} \\
\hline & & $d x s$ & rep & $d x s$ & rep & \\
\hline pBBR1MCS-2 & 30 & $15.97 \pm 0.03$ & $12.34 \pm 0.03$ & $2.45 \times 10^{8}(2.2 \%)$ & $4.78 \times 10^{9}(2.0 \%)$ & \multirow{2}{*}{$19.56(1.2 \%)^{d}$} \\
\hline pBBR1MCS-2 & 30 & $14.87 \pm 0.06$ & $11.23 \pm 0.07$ & $5.11 \times 10^{8}(3.8 \%)$ & $1.00 \times 10^{10}(4.7 \%)$ & \\
\hline pBBR1MCS-2 & 42 & $15.00 \pm 0.10$ & $12.36 \pm 0.05$ & $4.68 \times 10^{8}(6.4 \%)$ & $4.72 \times 109(3.4 \%)$ & $10.07(6.9 \%)^{d}$ \\
\hline pBBR1MCS-2-Ts & 30 & $14.83 \pm 0.05$ & $12.93 \pm 0.12$ & $5.24 \times 10^{8}(3.3 \%)$ & $3.22 \times 10^{9}(7.8 \%)$ & \multirow{2}{*}{$6.16(4.7 \%)^{\mathrm{d}}$} \\
\hline pBBR1MCS-2-Ts & 30 & $15.24 \pm 0.05$ & $13.34 \pm 0.10$ & $3.98 \times 10^{8}(3.1 \%)$ & $2.45 \times 10^{9}(5.3 \%)$ & \\
\hline pBBR1MCS-2-Ts & 42 & $14.49 \pm 0.07$ & $21.20 \pm 0.08$ & $6.59 \times 10^{8}(4.7 \%)$ & $1.28 \times 10^{7}(5.4 \%)$ & \multirow{2}{*}{$0.02(8.1 \%)$} \\
\hline pBBR1MCS-2-Ts & 42 & $14.66 \pm 0.06$ & $21.59 \pm 0.05$ & $5.90 \times 10^{8}(4.3 \%)$ & $9.82 \times 10^{6}(3.1 \%)$ & \\
\hline
\end{tabular}

${ }^{a}$ Average \pm standard deviation $(n=3)$

${ }^{\mathrm{b}}$ Average (coefficient of variation) $(\mathrm{n}=3)$.

${ }^{\mathrm{c}}$ Average (coefficient of variation) $(\mathrm{n}=6)$.

${ }^{\mathrm{d}}$ Asterisks indicate significant differences $(\mathrm{P}<0.01)$.

19.43 when cultured at $30^{\circ} \mathrm{C}$ and 10.04 when cultured at $42^{\circ} \mathrm{C}$, and the PCN of pBBR1MCS2-Ts was 6.13 when cultured at $30^{\circ} \mathrm{C}$ and 0.01 when cultured at $42^{\circ} \mathrm{C}$. These results were similar to those from absolute quantification.

\section{Discussions}

The pBBR1-derived series broad host range plasmids including pBBR1MCS2 are relatively small, replicate in a variety of Gram-negative organisms, and are mobilizable and compatible with various plasmid incompatibility groups $(18,29)$. The pBBR1-derived plasmids have been widely used as cloning and expression vectors in in laboratory (3034). To develop gene targeting and integration systems for board range host using pBBR1-derived plasmids, it is useful to modify the plasmid that can be lost efficiently from the hosts. Such plasmids' stability mainly depends on the stability of replication. Unfortunately, the replication mechanism of pBBR1-derived plasmids is still unknown. It was reported that the replication of pBBR1 required the expression of rep ORF. Therefore, we tried to randomly mutate the rep gene and its promoter and terminator by error prone PCR using pBBR1-derived plasmid pBBR1MCS2.

The mutated plasmid pBBR1MCS2-Ts remains stable at permissive temperature and was lost from the host $E$. coli at nonpermissive temperature. Sequence analysis indicated that pBBR1MCS-2-Ts had 3 points mutation: a mutation of $\mathrm{T}$ to $A$ at nucleotide number -43 (relative to translation start site of rep); a mutation of A to $\mathrm{G}$ at nucleotide number 73 , resulting a codon change of lysine (Lys) to glutamic acid (Glu) at residue number 25 of REP protein; a mutation of A to $G$ at nucleotide number 436 , resulting a codon change of isoleucine (Ile) to valine (Val) at residue number 145 of $R E P$ protein (20). Further point mutation revealed that the mutation of Lys to Glu at residue number 25 of REP protein causes the plasmid replication to be temperature sensitive.

To further explore the relationship between the stability of the plasmid and the plasmid copy number, absolute and relative quantitation PCR were used to determinate the plasmid copy number of original plasmid (pBBR1MCS2) and the derived temperature sensitive plasmid (pBBR1MCS2-Ts) in E. coli. In all respects, the results by the absolute and relative quantitation PCR were similar and reproducible. The plasmid copy number (PCN) of pBBR1MCS2 in E. coli was about 19 when cultured at $30^{\circ} \mathrm{C}$ and about 10 when cultured at $42^{\circ} \mathrm{C}$, and the PCN of pBBR1MCS2-Ts was about 6 when cultured at $30^{\circ} \mathrm{C}$ and nearly zero when cultured at $42^{\circ} \mathrm{C}$. Both of pBBR1MCS2 and pBBR1MCS2-Ts decrease PCN at $42^{\circ} \mathrm{C}$. The temperature shift from $30^{\circ} \mathrm{C}$ to $42^{\circ} \mathrm{C}$ caused a decrease in the PCN of pBBR1MCS2, which means the stability of pBBR1MCS2 could be affected by temperature. Furthermore, temperature shift from $30^{\circ} \mathrm{C}$ to $42^{\circ} \mathrm{C}$ caused a significant decrease in the PCN of pBBR1MCS2-Ts, meaning that the temperature sensitivity is mainly caused by the mutation of rep ORF, which subsequently affects the plasmid replication and stability. The mutation of Lys to Glu at residue number 25 of REP protein will be an interesting candidate for future mechanistic studies.

\section{Acknowledgments}

This study was supported by national natural science foundation of China (Grant No. 30970047) and natural science foundation of Fujian, China (Grant No. 2016J01147). 
Table 3. Determining the Plasmid Copy Number of pBBR1MCS-2 and pBBR1MCS-2-Ts in E.coli by Relative Quantification ${ }^{\mathrm{a}}$

\begin{tabular}{|c|c|c|c|c|c|}
\hline E. coli Harboring Plasmid & Culture Temperature, ${ }^{\circ} \mathrm{C}$ & $\Delta$ CT Sample $(n=3)$ & Calibrator $(\mathbf{n}=\mathbf{8})^{\mathbf{b}}$ & $\Delta \Delta C T(\mathbf{n}=3)$ & $\operatorname{PCN}^{\mathrm{C}}\left(1.95^{-\Delta \Delta \mathrm{C}_{\mathrm{T}}}\right)$ \\
\hline pBBR1MCS-2 & 30 & $-3.63 \pm 0.05$ & $0.81 \pm 0.03$ & $-4.44 \pm 0.04$ & \multirow{2}{*}{$19.43(2.3 \%)^{d}$} \\
\hline pBBR1MCS-2 & 30 & $-3.64 \pm 0.10$ & $0.81 \pm 0.03$ & $-4.45 \pm 0.03$ & \\
\hline pBBR1MCS-2 & 42 & $-2.64 \pm 0.11$ & $0.81 \pm 0.03$ & $-3.45 \pm 0.12$ & \multirow{2}{*}{$10.04(6.7 \%)^{\mathrm{d}}$} \\
\hline pBBR1MCS-2 & 42 & $-2.63 \pm 0.02$ & $0.81 \pm 0.03$ & $-3.44 \pm 0.04$ & \\
\hline pBBR1MCS-2-Ts & 30 & $-1.90 \pm 0.13$ & $0.81 \pm 0.03$ & $-2.71 \pm 0.08$ & \multirow{2}{*}{$6.13(4.8 \%)^{d}$} \\
\hline pBBR1MCS-2-Ts & 30 & $-1.90 \pm 0.11$ & $0.81 \pm 0.03$ & $-2.71 \pm 0.07$ & \\
\hline pBBR1MCS-2-Ts & 42 & $6.71 \pm 0.11$ & $0.81 \pm 0.03$ & $5.90 \pm 0.03$ & \multirow{2}{*}{$0.01(8.0 \%)$} \\
\hline pBBR1MCS-2-Ts & 42 & $6.93 \pm 0.08$ & $0.81 \pm 0.03$ & $6.12 \pm 0.03$ & \\
\hline
\end{tabular}

${ }^{\mathrm{a}}$ Values are expressed as mean $\pm \mathrm{SD}$.

${ }^{b}$ Calculated from the serial dilutions of the quantitative standard sample used for standard curve construction.

${ }^{c}$ Average (Coefficient of variation) $(n=6)$.

${ }^{\mathrm{d}}$ Asterisks indicate significant differences $(\mathrm{P}<0.01)$.

\section{Footnote}

Authors' Contribution: Conceived and designed the experiments: Jianzhong Huang and Yong Tao; performed the experiments: Xianzhang Jiang, Hongjiao Liu and Yongchao Niu; analyzed the data: Meirong Hu, Feng Qi and Mingliang Zhang; wrote the paper: Xianzhang Jiang and Hongjiao Liu.

\section{References}

1. Huang H, Zheng G, Jiang W, Hu H, Lu Y. One-step high-efficiency CRISPR/Cas9-mediated genome editing in Streptomyces. Acta Biochim Biophys Sin (Shanghai). 2015;47(4):231-43. doi: 10.1093/abbs/gmv007. [PubMed: 25739462].

2. Chen J, Ram G, Yoong P, Penades JR, Shopsin B, Novick RP. An rpsLbased allelic exchange vector for Staphylococcus aureus. Plasmid. 2015;79:8-14. doi:10.1016/j.plasmid.2015.02.002. [PubMed: 25659529].

3. Hoffmann F, Rinas U. Plasmid amplification in Escherichia coli after temperature upshift is impaired by induction of recombinant protein synthesis. Biotechnol Lett. 2001;23(22):1819-25. doi: 10.1023/a:1012718200638.

4. Budiharjo A, Chowdhury SP, Dietel K, Beator B, Dolgova O, Fan B, et al. Transposon mutagenesis of the plant-associated Bacillus amyloliquefaciens ssp. plantarum FZB42 revealed that the nfrA and RBAM17410 genes are involved in plant-microbe-interactions. PLoS One. 2014;9(5):ee98267. doi: 10.1371/journal.pone.0098267. [PubMed: 24847778].

5. Hashimoto-Gotoh T, Yamaguchi M, Yasojima K, Tsujimura A, Wakabayashi Y, Watanabe Y. A set of temperature sensitive-replication/segregation and temperature resistant plasmid vectors with different copy numbers and in an isogenic background (chloramphenicol, kanamycin, lacZ, repA, par, polA). Gene. 2000;241(1):185-91. [PubMed: 10607913].

6. Sugimoto M, Kojima H, Tanaka A, Matsui H, Sato K, Nakamatsu T. Temperature-sensitive plasmid. Google Patents; 1998.

7. Gruss A, Maguin E. Institut National De La Recherche Agronomique, assignee. Temperature-sensitive plasmid. US patent; 2000.

8. Bramucci MG. Temperature sensitive mutant derivatives of the broad host range plasmid pBHR1. Google Patents; 2006.
9. Lee CL, Ow DS, Oh SK. Quantitative real-time polymerase chain reaction for determination of plasmid copy number in bacteria. J Microbiol Methods. 2006;65(2):258-67. doi: 10.1016/j.mimet.2005.07.019. [PubMed: 16181694].

10. Zhong C, Peng D, Ye W, Chai L, Qi J, Yu Z, et al. Determination of plasmid copy number reveals the total plasmid DNA amount is greater than the chromosomal DNA amount in Bacillus thuringiensis YBT1520. PLoS One. 2011;6(1):ee16025. doi: 10.1371/journal.pone.0016025. [PubMed: 21283584].

11. Weisblum B, Graham MY, Gryczan T, Dubnau D. Plasmid copy number control: isolation and characterization of high-copy-number mutants of plasmid pE194. J Bacteriol. 1979;137(1):635-43. [PubMed: 104975].

12. Projan SJ, Carleton S, Novick RP. Determination of plasmid copy number by fluorescence densitometry. Plasmid. 1983;9(2):182-90. [PubMed: 6344110].

13. Genthner FJ, Hook LA, Strohl WR. Determination of the molecular mass of bacterial genomic DNA and plasmid copy number by high-pressure liquid chromatography. Appl Environ Microbiol. 1985;50(4):1007-13. [PubMed: 4083871].

14. Fujimura $\mathrm{H}$, Sakuma Y, Weimer T. A quantitative method for the determination of plasmid copy number in recombinant yeast. Biologicals. 1996;24(1):67-70. [PubMed: 8733603].

15. Breuer S, Marzban G, Cserjan-Puschman M, Durrschmid E, Bayer K. Off-line quantitative monitoring of plasmid copy number in bacterial fermentation by capillary electrophoresis. Electrophoresis. 1998;19(14):2474-8. doi: 10.1002/elps.1150191420. [PubMed: 9820970].

16. Lee C, Kim J, Shin SG, Hwang S. Absolute and relative QPCR quantification of plasmid copy number in Escherichia coli. J Biotechnol. 2006;123(3):273-80. doi: 10.1016/j.jbiotec.2005.11.014. [PubMed: 16388869].

17. Carapuca E, Azzoni AR, Prazeres DM, Monteiro GA, Mergulhao FJ. Time-course determination of plasmid content in eukaryotic and prokaryotic cells using real-time PCR. Mol Biotechnol. 2007;37(2):1206. [PubMed: 17914172$]$.

18. Kovach ME, Elzer PH, Hill DS, Robertson GT, Farris MA, Roop R2, et al. Four new derivatives of the broad-host-range cloning vector pBBR1MCS, carrying different antibiotic-resistance cassettes. Gene. 1995;166(1):175-6. [PubMed: 8529885].

19. Antoine $\mathrm{R}$, Locht $\mathrm{C}$. Isolation and molecular characterization of a novel broad-host-range plasmid from Bordetella bronchiseptica with sequence similarities to plasmids from gram-positive organisms. Mol Microbiol. 1992;6(13):1785-99. [PubMed: 1321324]. 
20. Jiang X, Huang J, Liu H, Zhou F, Zhang M, Qi F. Fujian Normal University, assignee. The temperature sensitive plasmid pBBR1mcs-2-ts4 and uses thereof. CN patent; 2015.

21. Hahn FM, Eubanks LM, Testa CA, Blagg BS, Baker JA, Poulter CD. 1Deoxy-D-xylulose 5-phosphate synthase, the gene product of open reading frame (ORF) 2816 and ORF 2895 in Rhodobacter capsulatus. J Bacteriol. 2001;183(1):1-11. doi: 10.1128/JB.183.1.1-11.2001. [PubMed: 11114895].

22. Gibson DG, Young L, Chuang RY, Venter JC, Hutchison C3, Smith HO. Enzymatic assembly of DNA molecules up to several hundred kilobases. Nat Methods. 2009;6(5):343-5. doi: 10.1038/nmeth.1318. [PubMed: 19363495].

23. Tombline G, Bartholomew LA, Urbatsch IL, Senior AE. Combined mutation of catalytic glutamate residues in the two nucleotide binding domains of P-glycoprotein generates a conformation that binds ATP and ADP tightly. J Biol Chem. 2004;279(30):31212-20. doi: 10.1074/jbc.M404689200. [PubMed:15159388].

24. Dhanasekaran S, Doherty TM, Kenneth J, T. B. Trials Study Group . Comparison of different standards for real-time PCR-based absolute quantification. J Immunol Methods. 2010;354(1-2):34-9. doi: 10.1016/j.jim.2010.01.004. [PubMed: 20109462].

25. Yu Y, Lee C, Kim J, Hwang S. Group-specific primer and probe sets to detect methanogenic communities using quantitative real-time polymerase chain reaction. Biotechnol Bioeng. 2005;89(6):670-9. doi: 10.1002/bit.20347. [PubMed: 15696537].

26. Cikos S, Bukovska A, Koppel J. Relative quantification of mRNA: comparison of methods currently used for real-time PCR data analysis. BMC Mol Biol. 2007;8:113. doi: 10.1186/1471-2199-8-113. [PubMed: 18093344].
27. Livak KJ, Schmittgen TD. Analysis of relative gene expression data using real-time quantitative PCR and the 2(-Delta Delta C(T)) Method Methods. 2001;25(4):402-8. doi: 10.1006/meth.2001.1262. [PubMed 11846609].

28. Reed GF, Lynn F, Meade BD. Use of coefficient of variation in assessing variability of quantitative assays. Clin Diagn Lab Immunol. 2002;9(6):1235-9. [PubMed:12414755].

29. Kovach ME, Phillips RW, Elzer PH, Roop R2, Peterson KM. pBBR1MCS: a broad-host-range cloning vector. Biotechniques. 1994;16(5):800-2. [PubMed: 8068328].

30. Elzer PH, Kovach ME, Phillips RW, Robertson GT, Peterson KM, Roop $\mathrm{R} 2$. In vivo and in vitro stability of the broad-host-range cloning vector pBBR1MCS in six Brucella species. Plasmid. 1995;33(1):51-7. doi: 10.1006/plas.1995.1006. [PubMed: 7753908].

31. DeShazer D, Woods DE. Broad-host-range cloning and cassette vectors based on the R388 trimethoprim resistance gene. Biotechniques. 1996;20(5):762-4. [PubMed: 8723912].

32. Obranic S, Babic F, Maravic-Vlahovicek G. Improvement of pBBR1MCS plasmids, a very useful series of broad-host-range cloning vectors. Plasmid. 2013;70(2):263-7. doi: 10.1016/j.plasmid.2013.04.001. [PubMed: 23583732].

33. Gruber S, Schwab H, Koefinger P. Versatile plasmid-based expression systems for Gram-negative bacteria-General essentials exemplified with the bacterium Ralstonia eutropha H16. N Biotechnol. 2015;32(6):552-8. doi: 10.1016/j.nbt.2015.03.015. [PubMed: 25865178].

34. Tian M, Qu J, BaoY, Gao J, Liu J, Wang S, et al. Construction of pTM series plasmids for gene expression in Brucella species.J Microbiol Methods. 2016;123:18-23. doi: 10.1016/j.mimet.2016.02.004. [PubMed: 26851674] 